\title{
A novel and cleaner bio-polymer Gum Karaya-based Silica nanocomposite fracturing fluid for high-temperature application
}

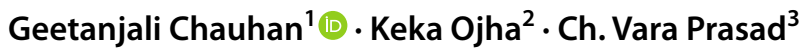

Received: 8 July 2021 / Accepted: 29 July 2021 / Published online: 5 August 2021

(c) The Author(s) 2021, corrected publication 2021

\begin{abstract}
A novel polymer nanocomposite has been synthesized in the present study using a bio-polymer Karaya and inorganic $\mathrm{SiO}_{2}$ nanoparticles via sonication for application as a fracturing fluid in stimulating oil and gas wells. Gum Karaya (KG), an acidic polysaccharide, has been investigated for its structural, morphological and rheological characteristics, and the results have been compared with prepared $\mathrm{KG}-\mathrm{SiO}_{2}$ nanocomposite at different $\mathrm{SiO}_{2}$ dosing for improved structure, viscoelasticity, viscosity and temperature stability. Steady shear rheology test depicted pseudoplastic nature, while oscillatory study confirms gel characteristics and weak dependence of storage and loss moduli on frequency for all the prepared samples. Dominance of elasticity over viscous nature of the gel assures efficient solid transporting/suspending capability. Experimental results showed that the rheological characteristics of the synthesized gel is comparable with Guar and CMHPG over the shear and temperature ranges under study and suitable for temperatures above $150{ }^{\circ} \mathrm{C}$ and pressure conditions. Also, polymer breaking and sandpack regained permeability tests proved synthesized gels to be a cleaner with less residue as compared to the other two.
\end{abstract}

Keywords Nanocomposite $\cdot$ Bio-polymer-Karaya $\cdot$ Thermal stability $\cdot$ Rheology $\cdot$ Gel breaking $\cdot$ Hydraulic fracturing

\section{Introduction}

The recent technological advancement in hydraulic fracturing (HF) has significantly enhanced the oil and gas production worldwide, especially in the USA. HF-a stimulation technique improves the reservoir permeability by utilizing fracturing fluid to create a fracture in the formation and to carry and place the proppant into the fracture. Conventionally, the water-soluble polymers like Guar and its derivatives like Carboxyl Methyl Hydroxyl Propyl Guar (CMHPG) in linear or metal ions-cross-linked form are being used as thickening agents to develop sufficiently high viscosity to

Geetanjali Chauhan

geetanjalichauhan2008@gmail.com

1 Department of Petroleum Engineering and Earth Sciences, University of Petroleum and Energy Studies, Dehradun, India

2 Department of Petroleum Engineering, Indian Institute of Technology (Indian School of Mines), Dhanbad 826004, India

3 Department of Chemical Engineering, University of Petroleum and Energy Studies, Dehradun, India fracture the formation under high-pressure and to carry the proppant to the fracture. It is desirable that these highly viscous gels should maintain their stability till the fracture opening and should be broken into a low viscosity fluid as soon as the proppant is placed into the fractures (Song et al. 2016; Yegin et al. 2016). However, partially or unbroken polymeric fluids generate residues upon breaking, causing a significant reduction in the effective permeability by clogging the pores of the formation and the proppant pack. The damage caused by these polymer fluids becomes more severe at high-temperature and high-pressure (HTHP) conditions where high polymer concentration is used to maintain the thermal stability. Application of nanotechnology for developing "smart nanofluids" could be adopted to solve this formation damage problem. These nanofluids have exceptionally high surface-to-volume ratio that provides the advantages of high thermal stability, elasticity, viscosity and wettability alteration to operate in HTHP conditions of the reservoir without increasing the polymer concentration (Cocuzza et al. 2011; Matteo et al. 2012; Song et al. 2016; Yegin et al. 2016).

In the last two decades, industrial sectors like pharmaceuticals, aerospace, automobile and oil and gas industry 
have paid strong emphasis for the evolution of polymeric nanocomposite, bearing at least one reinforcing component with nanometer range size (Henrique et al. 2009). In the oil and gas industry, nanotechnology is being used for noncorrosive material development, downhole separation processes and for enhanced oil and gas productivity (Matteo et al. 2012). Polymer-nanocomposites are novel materials and have attracted many researchers in the recent years due to their hybrid and synergistic properties with more interfacial adhesion, which provides exceptional optical, electrical, thermal and mechanical properties (elastic modulus, strength and dimension stability) (Paul and Robeson 2008; Henrique et al. 2009). However, these materials are rarely used in the oil industries and very little is known about the shear influence on the combined soft polymer with rigid inorganic nanoparticles, which is important in evaluating their efficiency at the downhole conditions (Paul and Robeson 2008; Henrique et al. 2009). Motivated with the novel characteristics of nanopolymer composites and the problem faced in hydraulic fracturing with the polymers, a nanocomposite has been developed as a hydraulic fracturing fluid (HFF) with silicon dioxide nanoparticles and Gum Karaya polymer, and various properties related to HFF were studied and compared with conventionally used polymers in oil industry. A natural bio-polymer Gum Karaya (KG), also called gum Sterculia, has been used in the present study as polymer for preparing the nanocomposite, which has also been used in our previous study to prepare zirconium-cross-linked HFF and was found effective upto a temperature of $150{ }^{\circ} \mathrm{C}$ (Chauhan et al. 2019). KG is obtained from the large and mature Sterculia urens grown extensively throughout the Indian sub-continent in arid forest regions. The gum has found its potential as an emulsifier, thickener and stabilizer in the food and pharmaceuticals industries (Abo-Shosha et al. 2008; Augusto et al. 2012; De Brito et al. 2005). Silicon dioxide offers promising support for the synthesis of bio-composite by developing active paramagnetic acid and base centers for mechanochemical reactions (Vorsina et al. 2011). In the present study, morphological, structural, sandpack regained permeability, steady state and dynamic rheology of aqueous solution of $\mathrm{KG}$ and $\mathrm{KG}-\mathrm{SiO}_{2}$ nanocomposite for improved properties have been studied and the results has been compared with conventional polymers like guar and CMHPG.

\section{Material and methods}

\section{Materials}

KG having molecular weight (MW) 950,000 Da and silicon dioxide $\left(\mathrm{SiO}_{2}\right)$ nanopowder having $99.5 \%$ purity and $15 \mathrm{~nm}$ average particle size were procured from SigmaAldrich, UK. CMHPG (MW $\left.1.31 \times 10^{6} \mathrm{Da}\right)$ was procured from Chem Total labs, Jodhpur, India and Guar Gum (MW $1.41 \times 10^{6} \mathrm{Da}$ ) from $\mathrm{CDH}$, India. All analytical grade chemicals were used directly to prepare gels in the distilled water.

\section{Methods}

\section{Polymer gel preparation}

Linear polymer gel samples were prepared by the adding desired quantity of polymer (KG, Guar or CMHPG) in distilled water at 1, 2 and $3 \mathrm{wt}$.\% concentrations with continuous stirring using a magnetic stirrer at $200 \mathrm{rpm}$ for $75 \mathrm{~min}$ at $50{ }^{\circ} \mathrm{C}$ for improved dispersion and swelling. For the preparation of polymer nanocomposite, first nanoparticles were dispersed in distilled water at desired concentration using solvent based exfoliation via sonication method with high shear and high impact mixing of $\mathrm{SiO}_{2}$ nanoparticles in solvent (water) for $1 \mathrm{~h}$ to improve interfacial bonding between the components and to prevent nanoparticles aggregation (Henrique et al. 2009). Upon completion of nanoparticles dispersion, polymer was added to this solution (Chauhan et al. 2017).

\section{Measurements}

\section{Infrared spectroscopy}

The infrared spectrum of the KG samples was observed in $3800-400 \mathrm{~cm}^{-1}$ frequency range using a PerkinElmer Fourier transform infrared spectroscopy (FTIR) instrument as described in our previous work, Chauhan et al. 2017.

\section{Morphological analysis}

Field Emission-Scanning Eectron Microscopy (FE-SEM) and Atomic Force Microscopy (AFM) analyses were conducted on $\mathrm{KG}$ and $\mathrm{KG}-\mathrm{SiO}_{2}$ nanoparticles samples using Carl Zeiss FE-SEM model-Supra 55 and Dimension Icon (Bruker AXS, Santa Barbara, CA, USA instruments), respectively, as described in detail in our previous work, Chauhan et al. 2017. The samples were diluted enough to describe the shape and size and also to reduce the aggregation risk upon drying.

\section{Rheological studies}

The rheological properties, both static and dynamic, were examined on a Bohlin Gemini rheometer as discussed in our previous work, Chauhan et al. 2017. The prepared gels were examined for thermal stability by observing the viscosity with time at various temperatures $\left(120^{\circ} \mathrm{C}, 150{ }^{\circ} \mathrm{C}\right.$ 
and $175^{\circ} \mathrm{C}$ ) in a high-pressure cell maintained at 900psi (restricted due to the instrumental constraint).

\section{Polymer breaking studies}

Ammonium persulfate (APS), an oxidative breaker, was used to observe the gel breaking for $\mathrm{KG}$, its nanocomposites, Guar and CMHPG gel samples at 1 and $3 \mathrm{wt} \%$ concentration. The gels after adding breaker were left for $24 \mathrm{~h}$ at $80^{\circ} \mathrm{C}$ to observe degradation with respect to time as discussed in our previous work, Chauhan et al. 2017.

\section{Sandpack regained permeability test}

The sandpack regained permeability test was performed using flooding experiment (Fig. 1) to determine the damage caused to the prepared sandpack by the broken fracturing fluid. The details of the experiment have been explained in our previous work, Chauhan et al. 2019.

\section{Result and discussions}

\section{Functional groups in KG and their variation on addition of nanoparticles}

$\mathrm{KG}$, an acidic polysaccharide, is chemically composed of galacturonic acid, sugars rhamnose and galactose (Chauhan et al. 2017). Figure 2 shows the result of FTIR analysis of $\mathrm{KG}$ (powder), $\mathrm{KG}$ fluid and $\mathrm{KG}-\mathrm{SiO}_{2}$ composite. The characteristic bands present in $\mathrm{KG}$ (powder) are: $3436 \mathrm{~cm}^{-1}$ for $\mathrm{O}-\mathrm{H}$ stretching band of the hydroxyl group, $1731 \mathrm{~cm}^{-1}$ for Acetyl group, $2928 \mathrm{~cm}^{-1}$ for $\mathrm{C}-\mathrm{H}$ in $\mathrm{CH}_{2}$ asymmetric stretching and $1614 \mathrm{~cm}^{-1}$ for asymmetrical stretching of carboxylate group or bound water

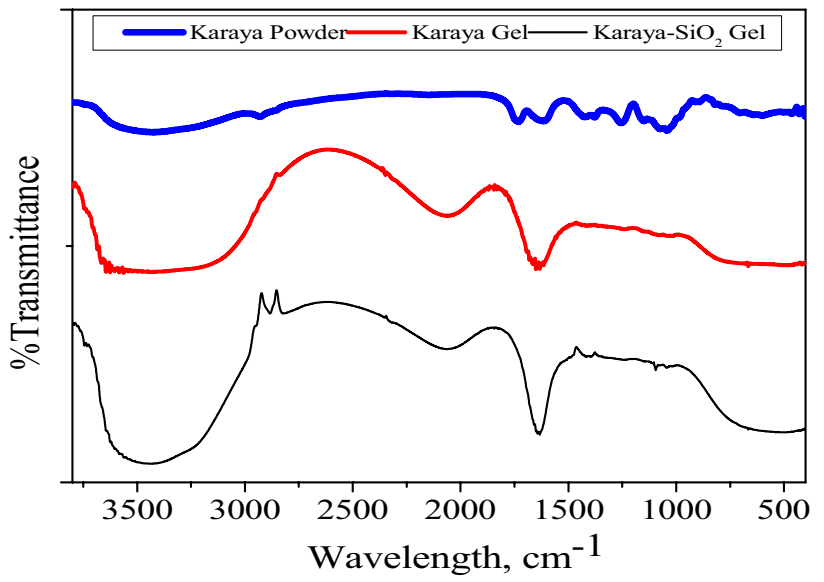

Fig. 2 Infrared spectrum $\left(400-3800 \mathrm{~cm}^{-1}\right)$ of $\mathrm{KG}$ Powder, $1 \% \mathrm{KG}$ gel and $1 \% \mathrm{KG}$ with $0.50 \% \mathrm{SiO}_{2}$

molecules. The bio-polymer on hydration has major peaks at $3436 \mathrm{~cm}^{-1}$ and $2060 \mathrm{~cm}^{-1}$ which reveals that bonding has happened between water and polymer molecules. A wide peak at $3436 \mathrm{~cm}^{-1}$ corresponds to the self-association of hydroxyl groups by hydrogen bonding. The peak at $1036 \mathrm{~cm}^{-1}$ representing the starch content in the powdered $\mathrm{KG}$ dissolved for the polymer gel system representing breaking of the inter-molecular starch bonds upon dilution in water and followed by the formation of the hydrogen bond at the open sites with more water molecules leading to swelling of polymer.

The reaction for the composition of inorganic-organic composite structure proceeds rapidly with hydrated silicon dioxide. The presence of acids in KG results in mechanochemical dehydration due to acid-base reaction when reacted with silanol group of $\mathrm{SiO}_{2}$ with the formation of $\mathrm{KG}-\mathrm{SiO}_{2}$ composite. According to the FTIR result, the

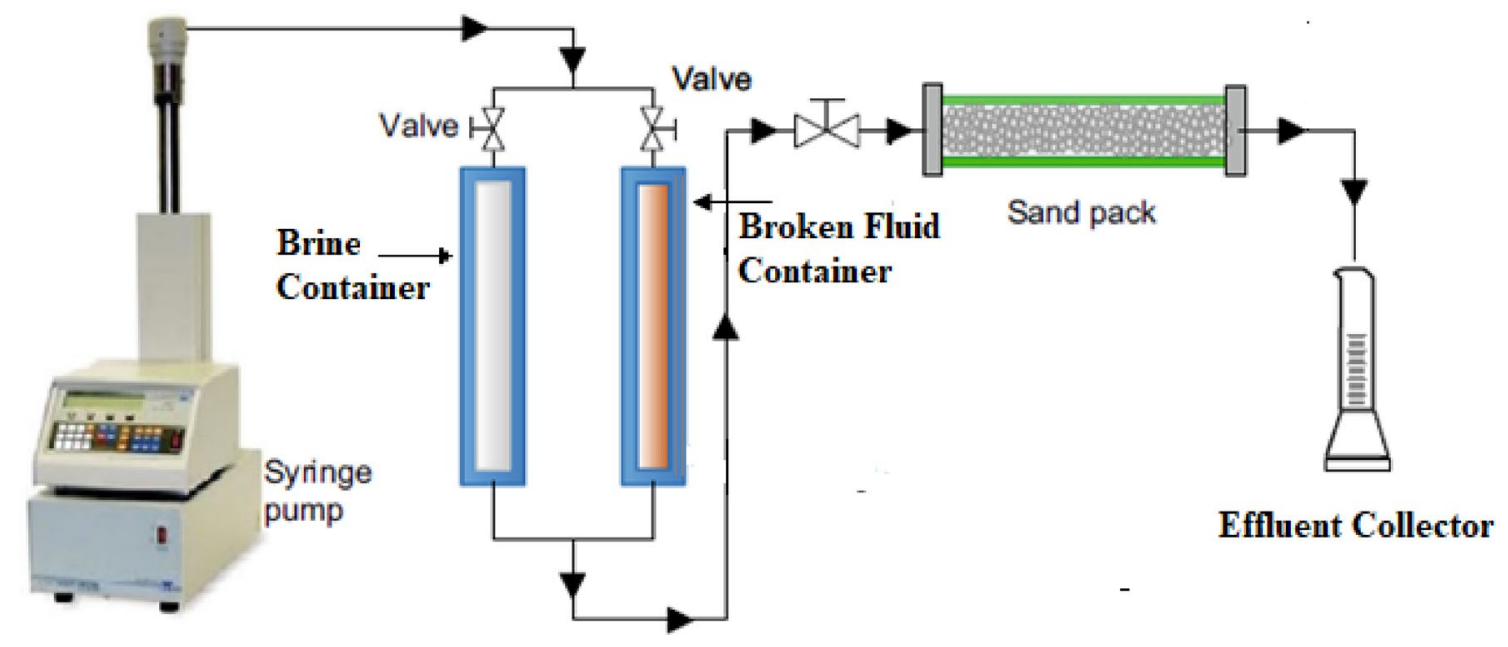

Fig. 1 Simplified design of experimental set up for sand pack flooding study (Chauhan et al. 2019) 
bridging bond $\mathrm{Si}-\mathrm{O}-\mathrm{C}$ is formed on the composite surface due to the reaction in Eq. 1.

$-\mathrm{COOH}+-\mathrm{SiOH} \rightarrow \mathrm{Si}-\mathrm{O}-\mathrm{C}+\mathrm{H}_{2} \mathrm{O}$

Figure 3 explains the possible reaction mechanism of $\mathrm{KG}-\mathrm{SiO}_{2}$ nanocomposite formation. The molecules of water absorbed on $\mathrm{SiO}_{2}$ act as the bonding link between acids present in $\mathrm{KG}$ and $\mathrm{SiO}_{2}$. The hydroxyl groups of acids and sugars present in $\mathrm{KG}$ react with acidic centers of $\mathrm{SiO}_{2}$, while the $-\mathrm{OH}$ group of $-\mathrm{COOH}$ of acids forms hydrogen bond with the molecules of absorbed water, which is again bonded with basic centers on $\mathrm{SiO}_{2}$ surface by hydrogen bonds (Watanabe et al. 2002; Abo-Shosha et al. 2008; Kizil et al. 2002). Thus, FTIR analysis confirms the formation of $\mathrm{KG}-\mathrm{SiO}_{2}$ nanocomposite via $\mathrm{Si}-\mathrm{CH}_{2}-\mathrm{Si}$ linkage through $-\mathrm{CH}_{2}$ group and $\mathrm{Si}-\mathrm{O}-\mathrm{C}$ association through $-\mathrm{OH}$ group.

\section{Morphological studies}

FE-SEM and AFM are powerful tools for the structural determination of bio-polymer nanocomposites using nanoparticles as reinforcing material. SEM and AFM images of $\mathrm{KG}$ fluid and $\mathrm{KG}-\mathrm{SiO}_{2}$ nanocomposite fluid are shown in Fig. 4. SEM images show the spherical appearance of polymer matrix with pores (dark areas) which confirms the amorphous nature of $\mathrm{KG}$ and reflects the higher water-binding capacity of the polymer (Fig. 4a, b). Sufficient contrast between nanoparticles and the KG matrix clearly shows the dispersion of $\mathrm{SiO}_{2}$ nanoparticles into the matrix. Even distribution of spherical nanoparticles in the dense polymer matrix could be noticed in the SEM images with some dense agglomeration or voids at some places (Fig. 4c). The morphology of the developed gel was further confirmed from the AFM study.

The AFM phase and the 3D height images for the polymer and nanocomposite fluid are presented in Figs. 4d-f. The phase image also confirmed the spherical networkshaped structure of KG with a more bright contrast than dark one and its 3D height image (Fig. 4e and f) which suggests the involvement of intra- and inter-molecular aggregation. The stiffer surface with high cross-link density is reflected in bright areas (hard silicon phase) and are uniformly distributed over the dark region which

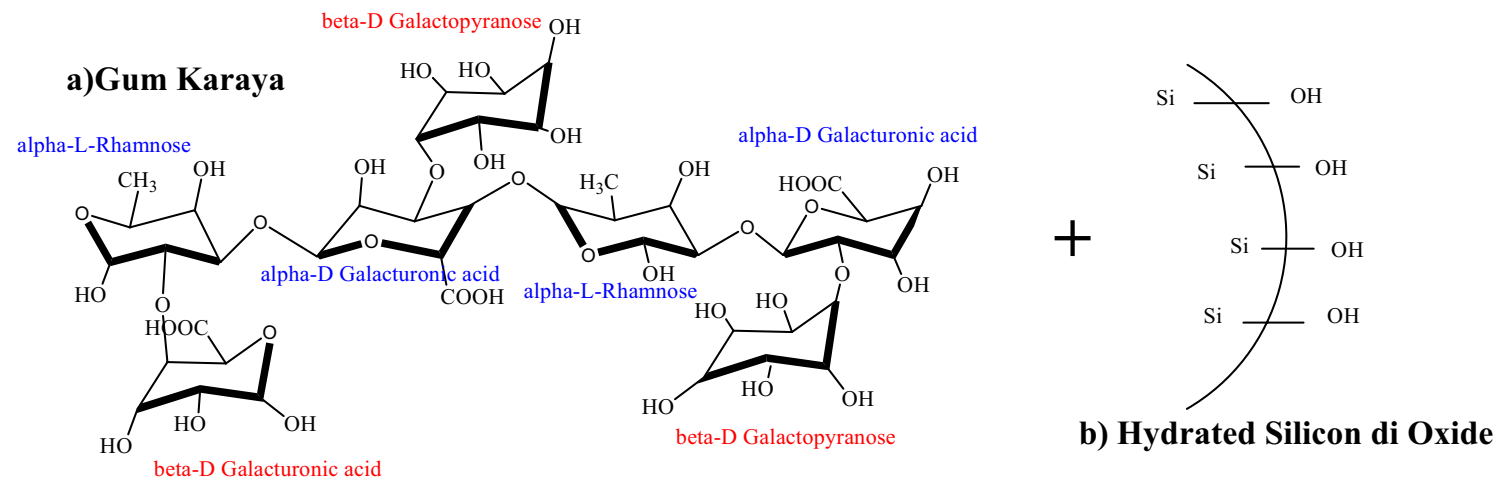

Solvent exfoliation via Sonication

$-\mathrm{COOH}+\mathrm{Si}-\mathrm{OH}$ (from alpha-D Galacturonic acid and beta-D Galacturonic acid)

$-\mathrm{CH}_{3}+\mathrm{Si}-\mathrm{OH}$ (from alpha-L-Rhamnose)

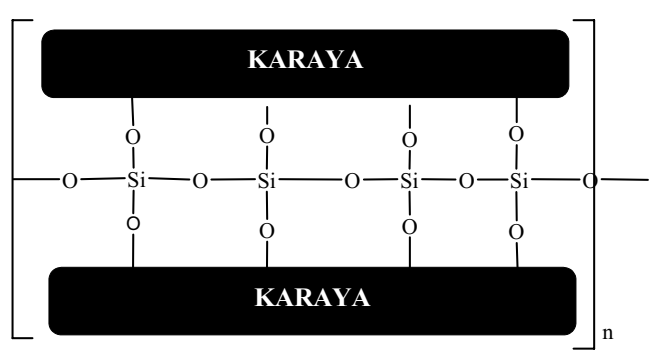

c) Karaya-SiO 2 composite

Fig. 3 Possible reaction mechanism for $\mathrm{KG}-\mathrm{SiO}_{2}$ nanocomposite formation 

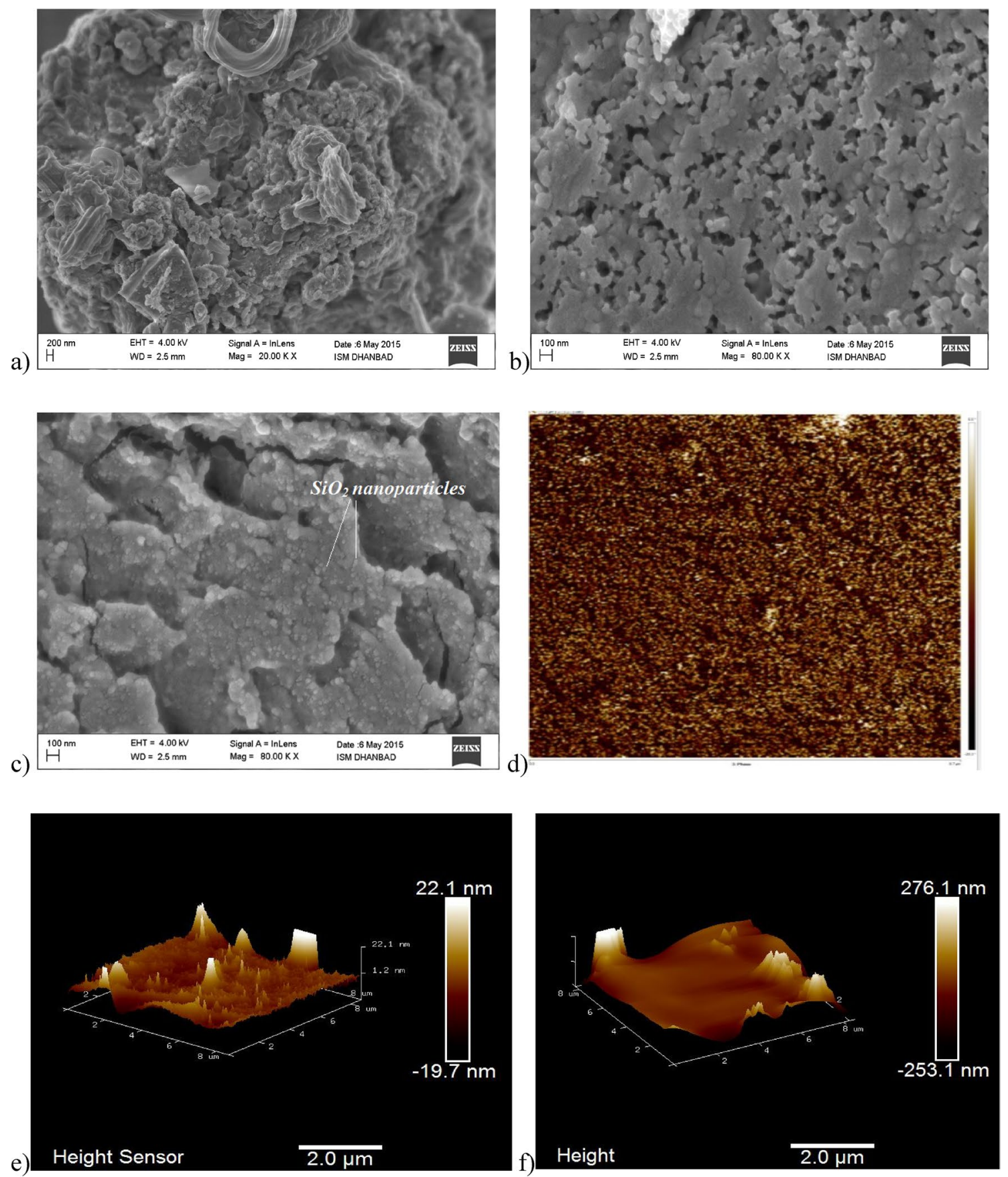

Fig. 4 SEM Images for a $\mathrm{KG}$ at $200 \mathrm{~nm}$, b $100 \mathrm{~nm}$ and c $\mathrm{KG}-\mathrm{SiO}_{2}$ nanoparticles at $100 \mathrm{~nm}$, d AFM phase image of KG-SiO ${ }_{2}$, e AFM 3-D height images for $\mathrm{KG}$ and $\mathbf{f} \mathrm{KG}-\mathrm{SiO}_{2}$ nanoparticles

corresponds to more viscous area with lower cross-link density (KG) (Isabel et al. 2012; Ulaganathan et al. 2012).

The Root Mean Square (RMS) roughness $\left(R_{\mathrm{q}}\right)$, the average roughness $\left(R_{\mathrm{a}}\right)$, the skew $\left(R_{\mathrm{sk}}\right)$ and kurtosis $\left(R_{\mathrm{ku}}\right)$ roughness parameters for the $\mathrm{KG}$ and $\mathrm{KG}-\mathrm{SiO}_{2}$ nanoparticle samples are presented in Table 1. Table 1 shows the synthesized nanocomposite resulted in increase in mean $\mathrm{R}_{\mathrm{a}}$ and a decrease in $R_{\text {sk }}$ which suggest an increase in the average
Table 1 Roughness parameters of $\mathrm{KG}$ and $\mathrm{KG}-\mathrm{SiO}_{2}$ nanoparticles thin films

\begin{tabular}{|c|c|c|c|c|}
\hline Sample & $R_{\mathrm{a}}$ & $R_{\mathrm{q}}$ & $R_{\mathrm{sk}}$ & $R_{\mathrm{ku}}$ \\
\hline KG film & 13.1 & 19.3 & 1.53 & 12.3 \\
\hline $\mathrm{KG}-\mathrm{SiO}_{2}$ & 19.7 & 26.9 & -0.501 & 4.77 \\
\hline
\end{tabular}


height of particles/agglomerate and dominance of depressions and valleys and is a criterion for well-defined globular structures with good bearing surface, i.e., high load carrying capacity and highly porous fluid film which could provide better shear and thermal resistance of the nanocomposite (Isabel et al. 2012; Kumar and Rao 2012; Hernández et al. 2007; Ulaganathan et al. 2012).

\section{Linear steady state rheology}

$\mathrm{KG}$ and $\mathrm{KG}-\mathrm{SiO}_{2}$ nanocomposite gel samples were investigated for rheological characterization at $1 \%, 2 \%$ and $3 \%$ polymer concentrations and 0.25 and $0.50 \% \mathrm{SiO}_{2}$ concentrations for increasing shear rate $\left(0.01-1000 \mathrm{~s}^{-1}\right)$ and temperature $\left(30-150{ }^{\circ} \mathrm{C}\right)$. The rheological results have been compared with Guar and CMHPG which are the most frequently used polymers in the industry (Fig. 5a and b). It is clear from Fig. 5 that viscosity decreases in the order Guar > CMHPG > KG for all three prepared concentrations, and it relates to reducing molecular weight.
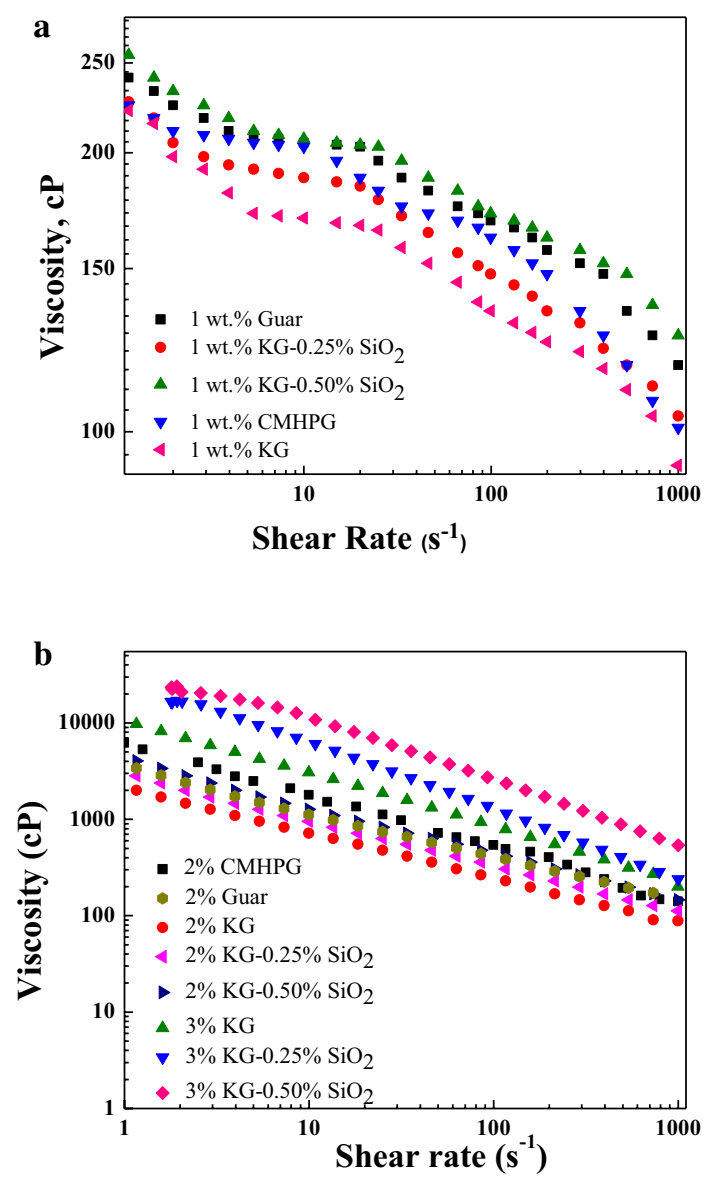

Fig. 5 a Viscosity variation with increasing shear rate for $1 \mathrm{wt} . \%$ polymer gel samples at $30{ }^{\circ} \mathrm{C}$. b Viscosity variation with increasing shear rate for 2 and $3 \mathrm{wt} \%$ polymer gel samples at $30^{\circ} \mathrm{C}$
KG suspensions are able to maintain comparable viscosities due to the presence of acetyl groups, in particularly galacturonic and glucuronic acid residues which promote interactions among polymeric chains and formation of gel network (De Brito et al. 2005). The viscosity increases as polymer concentration increases, mainly as a result of entanglement of the disordered polymer chains which increases with concentration.

Nanocomposite with $0.25 \% \mathrm{SiO}_{2}$ resulted in higher viscosity similar to CMHPG and $0.5 \% \mathrm{SiO}_{2}$ nanocomposite resulted in viscosities similar to guar at higher temperature ranges. Increasing the concentration of nanoparticles resulted in increased viscosity from 625 to $800 \mathrm{cP}$ at $150{ }^{\circ} \mathrm{C}$ at $100 \mathrm{~s}^{-1}$ for $3 \% \mathrm{KG}$ and from 180 to $300 \mathrm{cP}$ for $2 \% \mathrm{KG}$.

The energetically favorable interaction among nanoparticles clusters and polymer chains develops robust physical associations developing highly stable nanocomposite compared to the only polymer. This enhanced strength is mainly because of the viscous and rigid nature of clusters synergy, where the silane $(\mathrm{Si}-\mathrm{O}-\mathrm{C})$ covalent bonds support the plastic deformation and reversible physical hydrogen bonds ( $\mathrm{Si}-\mathrm{OH}$ and $\mathrm{Si}-\mathrm{CH}_{2}-\mathrm{C}$ ) provide nanocomposites flexibility and elastomeric nature. This synergy offers localized regions of enhanced strength that decay the growth of crack/hole upon deformation (Yang et al. 2013). The cluster formation can significantly influence the transfer of stress and heat in the network due to their porous structure and extensively effective volume fraction. To rephrase it, nanoparticles and polymer associate to develop an intramicelle "pseudocrosslinking," i.e., a 3D structure via various linkages and surface charge interactions. This results in enhanced viscosity due to robust dynamic polymeric network, direct morphology and rapid energy bust between rigid nanoparticles and soft polymer (Yang et al. 2013; Cassagnau 2013; Ji and Walz 2013; Crews and Huang 2008). From Fig. 5a and b, it could be observed that all the gels samples showed shear-thinning behavior which reduces friction during pumping and is always considered beneficial in a fracturing operation.

The increase in temperature $\left(40{ }^{\circ} \mathrm{C}\right.$ to $\left.150{ }^{\circ} \mathrm{C}\right)$ results in thermal thinning of the gel samples. However, from the results in Fig. $6 \mathrm{a}$ and b, it is evident that $1 \% \mathrm{KG}$ gels could maintain the required $90 \mathrm{cp}$ viscosity till $80{ }^{\circ} \mathrm{C}$ only which can be seen to improve to $120^{\circ} \mathrm{C}$ on the addition of 0.50 wt. $\% \mathrm{SiO}_{2}$ nanoparticles. The required $90 \mathrm{cP}$ at $100 \mathrm{~s}^{-1}$ viscosity comes from the rule of thumb applicable for fracturing fluids to suspend proppants and maintain required rheological properties during fracturing and prevailing reservoir temperature (Dantas et al. 2003; Baruah et al. 2014). Contrarily, 2 wt.\% KG and its nanocomposites at 0.25 wt. $\%$ and 0.50 wt. $\% \mathrm{SiO}_{2}$ (Fig. 6 b) always maintained 

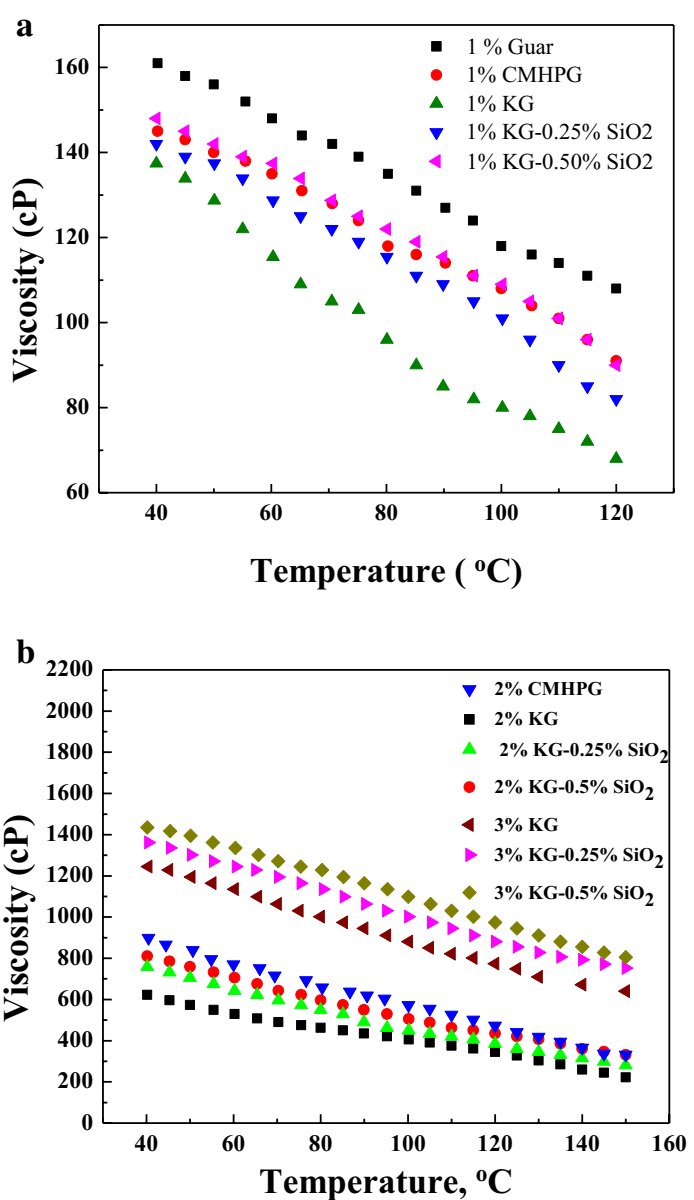

Fig. 6 a Temperature vs. viscosity for $1 \mathrm{wt}$ \% Polymer gel samples at $100 \mathrm{~s}^{-1}$. b Temperature vs. viscosity for 2 and 3 wt.\% Polymer gel samples at $100 \mathrm{~s}^{-1}$

their viscosities above $200 \mathrm{cP}$ at $150{ }^{\circ} \mathrm{C}$ which is superior to the recommended value of $90 \mathrm{cP}$ at $100 \mathrm{~s}^{-1}$.

\section{Oscillatory sweep measurements:}

Figure 7 shows the relationship between the frequency $(0.001$ to $15 \mathrm{~Hz})$ and the storage modulus $\left[G^{\prime}\right]$ and loss modulus $\left[G^{\prime \prime}\right]$ at $100{ }^{\circ} \mathrm{C}$ for 1 and $2 \mathrm{wt} . \%$ linear $\mathrm{KG}$ gels and their $\mathrm{SiO}_{2}(0.25$ and $0.50 \mathrm{wt} . \%)$ nanocomposites, and the various rheological parameters calculated for all the samples is presented in Table 2. No crossover point observed in the results in the studied frequency range indicates the weak dependence of $\mathrm{G}^{\prime}$ and $\mathrm{G}^{\prime \prime}$ on frequency and suggests the high particle suspension capability and longer relaxation time for the studied gels. The $G^{\prime}$ always retained higher value than the $G^{\prime \prime}$, depicting gel behavior with viscoelasticity where elasticity is dominant (Patel et al. 1992; Sodeifian et al. 2012). The $\mathrm{G}^{\prime}$ and $\mathrm{G}^{\prime} / \mathrm{G}^{\prime \prime}$ ratio values for all the synthesized samples showed a rising trend with the increase in the concentrations of nanoparticles and polymer (Table 2).

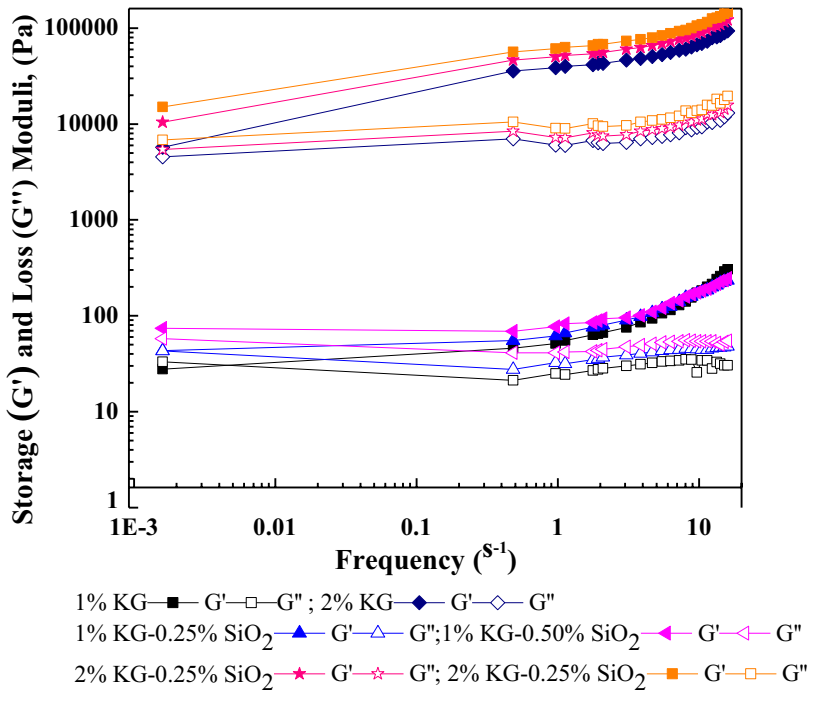

Fig. 7 Frequency Vs moduli (storage $\left(G^{\prime}\right)$ and loss $\left(G^{\prime \prime}\right)$ ) for 1 and 2 wt. $\% \mathrm{KG}$ and $\mathrm{KG}-\mathrm{SiO}_{2}$ nanocomposites $(0.25$ and 0.50 wt.\%) at $100{ }^{\circ} \mathrm{C}$

The prepared 1 wt.\% KG gel samples showed the soft nature of the gel, which implies an imbalance among the polymer chains, leading to defects like loose ends and loops in the polymer network (Grillet et al. 2012). However, the addition of nanoparticles into the polymer matrix resulted in enhanced gelling and elastic properties.

It could be observed from the Table 2 that for $2 \mathrm{wt} . \% \mathrm{KG}$ gels with and without nanoparticles showed the value of $G^{\prime} / G^{\prime \prime}$ greater than 3 which confirms the true nature of the gels. The increase in $G^{\prime}$ could be because of inter-particle interactions or the thermodynamic interactions between nanoparticle surface and the surrounding polymer matrix. The viscoelasticity is controlled by the dynamics of the slick-slip motion between the nanoparticle surface and the polymer chains, which increases the residence time of the entanglement near particle surface and results in reduced mobility of adsorbed chains and significantly diminished frequency dependence as compared to only polymer gel. This implies the formation of pseudo-solid-like three-dimensional

Table 2 Rheological Parameters for 1 and 2\% KG and their nanocomposite at $100{ }^{\circ} \mathrm{C}$ in the frequency range 0.01 to $1 \mathrm{~Hz}$

\begin{tabular}{lll}
\hline Sample & $\mathrm{G}^{\prime}[\mathrm{Pa}]$ & $\mathrm{G}^{\prime} / \mathrm{G}^{\prime \prime} \pm \mathrm{SD}$ \\
\hline $1 \% \mathrm{KG}$ & 45.01 & $1.978 \pm 0.472$ \\
$1 \% \mathrm{KG}-0.25 \% \mathrm{SiO}_{2}$ & 72.3 & $2.458 \pm 0.233$ \\
$1 \% \mathrm{KG}-0.50 \% \mathrm{SiO}_{2}$ & 86.3 & $2.896 \pm 0.568$ \\
$2 \% \mathrm{KG}$ & 38,152 & $5.453 \pm 2.65$ \\
$2 \% \mathrm{KG}-0.50 \% \mathrm{SiO}_{2}$ & 41,208 & $5.6789 \pm 1.365$ \\
$2 \% \mathrm{KG}-0.50 \% \mathrm{SiO}_{2}$ & 46,320 & $5.862 \pm 1.12$ \\
\hline
\end{tabular}


Table 3 Percentage residue generated after breaking gel

\begin{tabular}{|c|c|c|c|c|}
\hline \multirow{2}{*}{$\begin{array}{l}\text { Polymer Concentration } \\
\text { APS concentration }\end{array}$} & \multicolumn{2}{|l|}{$1 \mathrm{wt} . \%$} & \multicolumn{2}{|l|}{$2 \mathrm{wt} . \%$} \\
\hline & 1wt.\% & $3 \mathrm{wt} . \%$ & $1 \mathrm{wt} . \%$ & 3wt. $\%$ \\
\hline Guar & 26.2 & 25.3 & 59.31 & 49.98 \\
\hline CMHPG & 11.6 & 10.4 & 54.5 & 49.2 \\
\hline KG & 5.5 & 3.5 & 37 & 34.5 \\
\hline $\mathrm{KG}-0.50 \% \mathrm{SiO}_{2}$ & 5.8 & 3.7 & 36.7 & 35.1 \\
\hline
\end{tabular}

network due to hindered mobility of polymer chains and longer relaxation time at low frequencies (Sarvestani 2008).

\section{Polymer breaking study}

Post fracture, gel breaking is necessary so that low viscous broken fracturing fluid can flow back to the surface along with oil and gas. The final viscosity of all the gels broken using APS at 1 and 3\% concentration was found to be less than $2 \mathrm{cP}$ at room temperature. Table 3 shows the residue generated from Guar, CMHPG, $\mathrm{KG}$ and $\mathrm{KG}-\mathrm{SiO}_{2}$ nanocomposite, and it can be seen that $\mathrm{KG}$ gels yielded least residues. Even $\mathrm{KG}-\mathrm{SiO}_{2}$ composite gave the almost similar results as that of KG. The residue generated depends on the amount of natural residues present in polysaccharide, the molecular weight of polymer and the unbroken gel. KG has a lower molecular weight as compared to Guar and CMHPG. The addition of $\mathrm{SiO}_{2}$ nanoparticles in the composite provides significantly fewer residues as the polymer concentration is not increased, and $\mathrm{SiO}_{2}$ does not result in residue formation (Chauhan et al. 2017).

\section{Simulated field conditions rheology}

In actual, fracturing fluid during a hydraulic fracturing job is frequently exposed to the HTHP conditions, and it comes in contact with water-sensitive clays. Therefore, it is of utmost significance to study the combined effect of pressure and temperature on the rheological properties under the simulated field conditions, though it has been observed that the rheological properties of fracturing fluid are more sensitive to temperature than the operating pressure owing to its low isothermal compressibility (Fuhua et al. 2012; Sheng-ying et al. 2008). In the present probe, ethanol and $\mathrm{KCl}$ have been added to the prepared fluids as temperature stabilizers and an anti-clay swelling agent, respectively. They are frequently added in fracturing fluids to avoid clay swelling and for high-temperature applications. The effect of controlled pressure of 900psi (restricted due to instrumental constraint) and high-temperature (upto $175^{\circ} \mathrm{C}$ ) was studied on KG samples and its nanocomposites for one hour under time sweep experiments at $100 \mathrm{~s}^{-1}$ shear rate.
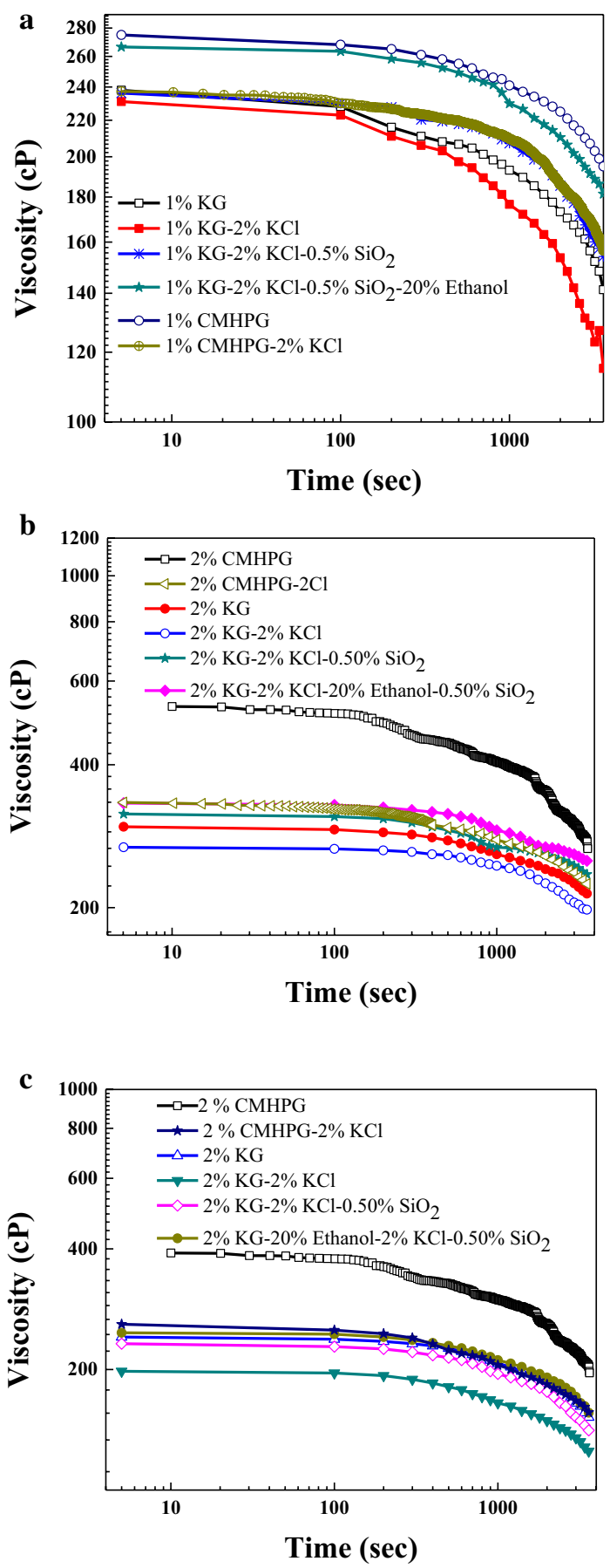

Fig. 8 a Viscosity vs. time (3600 s) for $1 \mathrm{wt} . \%$ polymer gels samples at $900 \mathrm{psi}$ and $120^{\circ} \mathrm{C}$. b Viscosity vs. time (3600 s) for $2 \mathrm{wt} . \%$ polymer gels samples at $900 \mathrm{psi}$ and $150{ }^{\circ} \mathrm{C}$. c Viscosity vs. time (3600 s) for $1 \mathrm{wt} . \%$ polymer gels samples at $900 \mathrm{psi}$ and $175^{\circ} \mathrm{C}$

From the results presented in Fig. $8 \mathrm{a}$, it is evident that 1 wt.\% KG is able to maintain its viscosity much higher than $90 \mathrm{cP}$ at $100 \mathrm{~s}^{-1}$ at $120^{\circ} \mathrm{C}$ and $900 \mathrm{psi}$ which is the minimum required viscosity for fracturing operation (Thampi et al. 2014). The thermal stability was found to enhance on the 
Table 4 Sand pack regained permeability percentage for various samples

\begin{tabular}{lllll}
\hline Sample treatment & $\begin{array}{l}\text { Porosity- sand- } \\
\text { pack, \% }\end{array}$ & $\begin{array}{l}\text { Permeability, before fluid } \\
\text { treatment, Darcy }\end{array}$ & $\begin{array}{l}\text { Permeability, after } \\
\text { treatment, Darcy }\end{array}$ & $\begin{array}{l}\text { Regained } \\
\text { permeabil- } \\
\text { ity, \% }\end{array}$ \\
\hline $1 \% \mathrm{KG}$ & 30.3 & 3.74 & 3.104 & 83 \\
$1 \% \mathrm{Guar}$ & 30.1 & 3.7205 & 2.5299 & 68 \\
$1 \% \mathrm{CMHPG}$ & 31.3 & 3.7791 & 2.7209 & 72 \\
$1 \% \mathrm{KG}-0.50 \% \mathrm{SiO}_{2}$ & 31.1 & 3.7652 & 3.0121 & 80 \\
\hline
\end{tabular}

inclusion of alcohol and nanoparticles. The $2 \mathrm{wt.} \% \mathrm{KG}$ and its nanocomposites were found suitable for higher temperature applications above $120^{\circ} \mathrm{C}$ as they maintained sufficient viscosity (Fig. 8a, c) upto $175^{\circ} \mathrm{C}$ at 900 psi. The inclusion of alcohols increases the polymer solubility in the less polar aqueous-alcoholic solvent system and enhances the polymer swelling (Balaghi et al. 2011; Chauhan et al. 2017).

The applied pressure did not affect the apparent viscosity over the studied time variable, and the viscosity values were found to be sufficient for the $1 \mathrm{~h}$ duration showing its effectiveness for fracturing application. The compressibility effect predominant over the applied pressure condition enhanced the thermal stability of the fluid under observation (Luo et al. 2014; Baruah et al. 2016).

\section{Sand pack regained permeability}

The oil and gas industry faces major challenges using polymer-based fracturing fluid to control the damage caused to the proppant pack and formation because of partial polymeric degradation and insoluble polymeric residues. The water-soluble polymers leave a significant amount of insoluble residues upon breaking, clogging pores, and thereby reducing the effective fracture permeability. The reduction in effective fracture permeability can be studied on a simulated sand pack system as described in our previous work (Chauhan et al. 2019). Table 4 presents the percentage regained permeability of the sand pack system studied by flowing broken fracturing fluids through the sand pack. From the table, it is evident that the linear KG gels and their nanocomposites offered superior regained permeability than guar and CMHPG. The higher regained permeability for KG samples is directly related to smaller molecular weight, size of $\mathrm{KG}$ and its better interaction with the breaker as compared to higher molecular weight polymers like Guar and CMHPG. The partial breaking of guar leads to pore blockages and reduced effective permeability (Cooke 1975; Almond 1982; Parker et al. 1994).

\section{Conclusions}

The KG-SiO 2 nanocomposites offered improved mechanical and rheological properties due to development of active paramagnetic acid and basic centers on the hydrated $\mathrm{SiO}_{2}$ surface for mechanochemical reactions. The prepared gels were more viscous, elastic and thermally stable as compared to pure polymer gels and resulted in viscosities similar to CMHPG and Guar but leave lower insoluble residues upon breaking. Also, the polymer nanocomposites resulted in increased elastic modulus value and the long time relaxation due to "strong associated particle" effect which leads to their superior proppant suspension capacity compared to all other polymer gels. Therefore, $\mathrm{KG}-\mathrm{SiO}_{2}$ nanocomposite gels could be considered as a promising candidate for their application in the oil industry as fracturing fluid owing to its improved rheology, thermal stability, breaking characteristics and cheaper cost as compared to CMHPG.

Funding The authors declare that no Funding was received for this work.

\section{Declarations}

Conflict of interest The authors declare that they have no conflict of interest.

Open Access This article is licensed under a Creative Commons Attribution 4.0 International License, which permits use, sharing, adaptation, distribution and reproduction in any medium or format, as long as you give appropriate credit to the original author(s) and the source, provide a link to the Creative Commons licence, and indicate if changes were made. The images or other third party material in this article are included in the article's Creative Commons licence, unless indicated otherwise in a credit line to the material. If material is not included in the article's Creative Commons licence and your intended use is not permitted by statutory regulation or exceeds the permitted use, you will need to obtain permission directly from the copyright holder. To view a copy of this licence, visit http://creativecommons.org/licenses/by/4.0/. 


\section{References}

Abo-Shosha MH, Ibrahim NA, Allam E, El-Zairy E (2008) Preparation and characterization of polyacrylic acid/karaya gum and polyacrylic acid/tamarind seed gum adducts and utilization in textile printing. Carbohydr Polym 74:241-249. https://doi.org/10.1016/j. carbpol.2008.02.011

Almond SW (1982) Factors affecting gelling agent residue under low temperature conditions. In: Presented at SPE formation damage control symposium, Lafayette, Louisiana, pp 24-25, SPE-10658-MS

Augusto PED, Cristianini M, Ibarz A (2012) Effect of temperature on dynamic and steady-state shear rheological properties of siriguela (Spondias purpurea L.) pulp. J Food Eng 108:283-289. https:// doi.org/10.1016/j.jfoodeng.2011.08.015

Balaghi S, Mohammadifar MA, Zaragaraan A, Gavloghi HA, Mohammadi M (2011) Compositional analysis and rheological characterization of gum tragacanth exudates from six species of iranian astragalus. Food Hydrocoll 25:1775-1784

Baruah A, Chauhan G, Ojha K, Pathak AK (2014) Phase behavior and thermodynamic and rheological properties of single- (Sds) and mixed-surfactant (Sds + Capb)-based fluids with 3-methylbutan1-Ol As the cosurfactant and pine oil as the organic phase. Ind Eng Chem Res 53:19765-19774

Baruah A, Shekhawat DS, Pathak AK, Ojha K (2016) Experimental investigation of rheological properties in zwitterionic-anionic mixed-surfactant based fracturing fluids. J Pet Sci Eng 146:340349. https://doi.org/10.1016/j.petrol.2016.05.001

Cassagnau P (2013) Linear viscoelasticity and dynamics of suspensions and molten polymers filled with nanoparticles of different aspect ratios. Polymer 54:4762-4775

Chauhan G, Verma A, Hazarika A, Ojha K (2017) Rheological, structural and morphological studies of Gum Tragacanth and its inorganic $\mathrm{SiO}_{2}$ nanocomposite for fracturing fluid application. J Taiwan Inst Chem Eng 80:978-988

Chauhan G, Verma A, Doley A, Ojha K (2019) Rheological and breaking characteristics of $\mathrm{Zr}$-crosslinked gum karaya gels for high-temperature hydraulic fracturing application. J Pet Sci Eng 172:327-339

Cocuzza M, Pirri F, Rocca V, Verga F, Torino P (2011) Is the oil industry ready for nanotechnologies? Offshore Mediterr. Conf. Exhib. $1-17$

Cooke CE (1975) Effect of fracturing fluids on fracture conductivity. J Pet Tech 27:1273-1282

Crews JB, Huang T (2008) performance enhancement of viscoelastic surfactant stimulation fluids with nanoparticles. presented at europec/eage conference and exhibition, 9-12 June, Rome, Italy, SPE-113533-MS

Dantas TNC, Santanna VC, Dantas Neto AA, Barros Neto EL (2003) Application of surfactants for obtaining hydraulic fracturing gel. Pet Sci Tech 21:1145-1157

De Brito ACF, Sierakowski MR, Reicher F, Feitosa JPA, De Paula RCM (2005) Dynamic rheological study of Sterculia striata and karaya polysaccharides in aqueous solution. Food Hydrocoll 19:861-867. https://doi.org/10.1016/j.foodhyd.2004.10.035

Fuhua W, Xuechao T, Ruihe W, Mingbo S, Li W, Jianghua L (2012) High temperature and high pressure rheological properties of high-density water based drilling fluids for deep wells. Pet Sci 9:354-362

Grillet AM, Wyatt NB, Gloe LB, De Vicente J (eds) (2012) Polymer gel rheology and adhesion, rheology. Intech

Henrique P, Camargo C, Satyanarayana KG, Wypych F (2009) Nanocomposites: Synthesis, structure, properties and new application opportunities. Mater Res 12:1-39. https://doi.org/10.1590/S151614392009000100002
Hernández JCR, Sánchez MS, Ribelles JLG, Pradas MM (2007) Polymer-silica nanocomposites prepared by sol-gel technique: nanoindentation and tapping mode AFM studies. Eur Polym J 43:2775-2783. https://doi.org/10.1016/j.eurpolymj.2007.04.021

Isabel A, Petrova K, Teresa M, Sotomayor J (2012) New polymer networks for PDLC films application, new polymers for special applications. IntechOpen. DOI: https://doi.org/10.5772/48203

Ji S, Walz JY (2013) Synergistic effects of nanoparticles and polymers on depletion and structural interactions. Langmuir 2:1515915167. https://doi.org/10.1021/la403473g

Kizil R, Irudayaraj J, Seetharaman K (2002) Characterization of irradiated starches by using FT-Raman and FTIR spectroscopy. J Agric Food Chem 50:3912-3918. https://doi.org/10.1021/jf011652p

Kumar BR, Rao TS (2012) AFM studies on surface morphology, topography and texture of nanostructured zinc aluminum oxide thin films. Dig J Nanomater Biostruct 7:1881-1889

Luo X, Wang S, Wang Z, Jing Z, Lv M (2014) Experimental research on rheological properties and proppant transport performance Of Grf-Co2 fracturing fluid. J Petro Sci Eng 20:154-162

Matteo C, Candido P, Vera R, Francesca V, Duca C, Abruzzi D (2012) Current and future nanotech applications in the oil industry. $\mathrm{J}$ Appl Sci 9:784-793

Parker MA, Vitthal S, Rahimi I, Mcgowen JM, Martch Jr WE (1994) Hydraulic Fracturing Of High-Permeability Formations To Overcome Damage. Presented At SPE Formation Damage Control Symposium, 7-10 February, Lafayette, Louisiana, SPE-27378-MS.

Patel SK, Malone S, Cohen C, Gillmor JR, Colby RH (1992) Elastic modulus and equilibrium swelling of poly (dimethylsiloxane) networks. Macromolecules 25:5241-5251

Paul DR, Robeson LM (2008) Polymer nanotechnology: nanocomposites. Polymer 49:3187-3204. https://doi.org/10.1016/j.polym er.2008.04.017

Sarvestani AS (2008) Modeling the solid-like behavior of entangled polymer nanocomposites at low frequency regimes. Eur Polym J 44:263-269. https://doi.org/10.1016/j.eurpolymj.2007.11.023

Sheng-Ying Z, Jie-Nian Y, Yong S, Hong-Xia Z (2008) Rheological properties of oil-based drilling fluids at high temperature and high pressure. J Cent South Uni Tech 15:457-461

Sodeifian G, Nikooamal HR, Yousefi AA (2012) Molecular dynamics study of epoxy/clay nanocomposites: Rheology and molecular confinement. J Polym Res 19:9897. https://doi.org/10.1007/ s10965-012-9897-2

Song J, Fan W, Long X, Zhou L, Wang C, Li G (2016) Rheological behaviors of fluorinated hydrophobically associating cationic guar gum fracturing gel. J Pet Sci Eng 146:999-1005. https://doi.org/ 10.1016/j.petrol.2016.08.013

Thampi NV, Ojha K, Nair UG (2014) Effect of Branched Alcohols on Phase Behavior and :Physicochemical Properties of Winsor IV Microemulsions. J Surfact Deterg 17:371-381

Ulaganathan M, Nithya R, Rajendran S (2012) Surface analysis studies on polymer electrolyte membranes using scanning electron microscope and atomic force microscope. Scanning electron microscopy. Intechopen. doi: https://doi.org/10.5772/34948.

Vorsina I, Grigorieva T, Barinova A, Lyakhov N (2011) Mechanochemical interaction of silicon dioxide with organic acids. Ariel. Ac. Il 19: 236-247

Watanabe T, Hasegawa S, Wakiyama N, Usui F, Kusai A, Isobe T, Senna M (2002) Solid state radical recombination and charge transfer across the boundary between indomethacin and silica under mechanical stress. J Solid State Chem 164:27-33. https:// doi.org/10.1006/jssc.2001.9436

Yang J, Han C, Duan J, Xu F, Sun R (2013) Interaction of silica nanoparticles/polymer nanocomposite cluster network structure: revisiting the reinforcement mechanism. J Phys Chem C $117: 8223-8230$ 
Yegin C, Zhang M, Talari JV, Akbulut M (2016) Novel hydraulic fracturing fluids with improved proppant carrying capacity and $\mathrm{pH}$ adjustable proppant deposition behavior. J Pet Sci Eng 145:1-26. https://doi.org/10.1016/j.petrol.2016.06.033
Publisher's Note Springer Nature remains neutral with regard to jurisdictional claims in published maps and institutional affiliations. 